\title{
LIDAR OBSERVATIONS OF MOUNTAIN WAVES DURING BORA EPISODES
}

\author{
Longlong Wang ${ }^{1^{*}}$, Marija Bervida ${ }^{1}$, Samo Stanič ${ }^{1}$, Klemen Bergant ${ }^{1,2}$, William Eichinger ${ }^{3}$ and \\ Benedikt Strajnar $^{2}$ \\ ${ }^{1}$ Center for Atmospheric Research, University of Nova Gorica, Nova Gorica, 5270, Slovenia \\ ${ }^{2}$ Slovenian Environment Agency, Ljubljana, 1000, Slovenia \\ ${ }^{3}$ Department of Civil and Environmental Engineering, University of Iowa, Iowa City, IA 52242, USA \\ *Email: longlong.wang@ung.si
}

\begin{abstract}
Airflows over mountain barriers in the Alpine region may give rise to strong, gusty downslope winds, called Bora. Oscillations, caused by the flow over an orographic barrier, lead to formation of mountain waves. These waves can only rarely be observed visually and can, in general, not be reliably reproduced by numerical models. Using aerosols as tracers for airmass motion, mountain waves were experimentally observed during Bora outbreak in the Vipava valley, Slovenia, on 24-25 January 2019 by two lidar systems: a vertical scanning lidar positioned just below the peak of the lee side of the mountain range and a fixed direction lidar at valley floor, which were set up to retrieve two-dimensional structure of the airflow over the orographic barrier into the valley. Based on the lidar data, we determined the thickness of airmass layer exhibiting downslope motion, observed hydraulic jump phenomena that gave rise to mountain waves and characterized their properties.
\end{abstract}

\section{INTRODUCTION}

Orographically-generated mountain waves occur when stably stratified airflow passes over a mountain ridge. These waves play an important role in redistributing momentum and energy, thus making a significant impact on the atmospheric dynamics both on the local and regional scale [1]. In the Alpine region, in particular in the Dinaric Alps along the Adriatic coast, mountain waves are, under certain synoptic conditions, related to the strong, cold and gusty downslope wind, called Bora [2,3]. Occurrences of mountain waves at heights considerably lower than the orographic barrier have been ascribed to hydraulic jumps in the Bora flow [4]. Although the role of mountain waves has been theoretically explained, their modeling remains a challenge due to the need for high temporal and spatial resolution as well as the non-periodic variability of Bora flow $[5,6]$. Systematic observations of airflow properties became possible with the advance of active remote sensing devices and techniques, for example by the use of a Doppler wind lidar or a scanning Mie lidar that exploits aerosols as tracers for air mass motion [7].

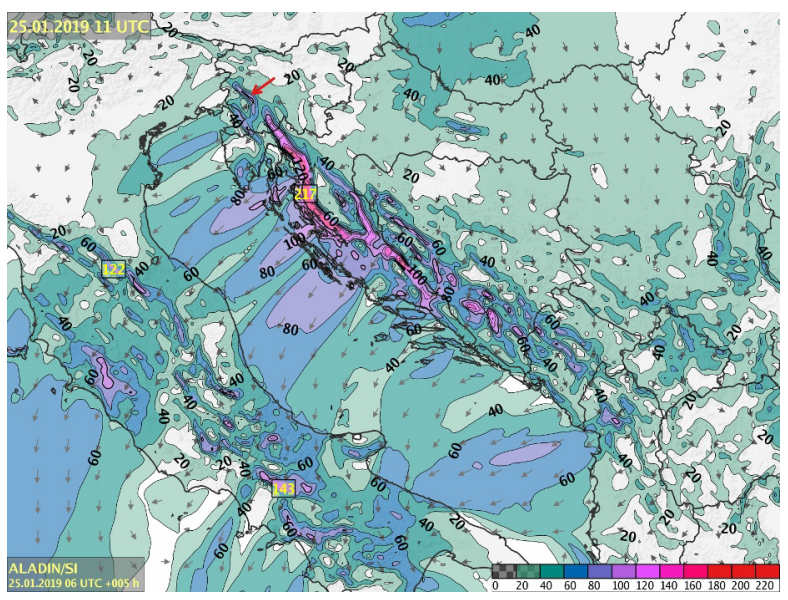

Fig. 1. ALADIN forecast of peak wind gust speeds during a major windstorm across the western Mediterranean on 25 January 2019 between 9:00 and 11:00 UTC. The location of the Vipava valley, where gust speeds exceeded $20 \mathrm{~m} / \mathrm{s}$, is denoted by a red arrow.

The aim of this study is to characterize the properties of mountain waves during a Bora outbreak based on lidar remote sensing and in-situ wind measurements. The Vipava valley in the SW Slovenia as our area of interest is ideal for this purpose being frequently exposed to strong Bora 
outbreaks with peak wind gust speeds exceeding $30 \mathrm{~m} / \mathrm{s}$.

\section{METHODOLOGY}

The Vipava valley is a deep mountain valley in southwestern Slovenia. Towards the Adriatic coast in the south-west, the valley (125 m above the sea level) is closed by the Karst plateau (up to $300 \mathrm{~m}$ a.s.l.), while to the north-east the terrain rises steeply to the Trnovski gozd plateau (up to 1200 $\mathrm{m}$ a.s.l.). Being at the uppermost part of the Dinaric Alps barrier (Fig. 1), it is frequently exposed to strong Bora outbreaks and can serve as a representative location for the study of Bora and mountain waves. Airflow structures on the lee side of the Trnovski gozd were investigated using simultaneous lidar and in-situ wind measurements at two locations (Fig. 2), one just below the peak of the ridge (Otlica, $951 \mathrm{~m}$ a.s.l.) and the other at the valley floor (Ajdovščina, $125 \mathrm{~m}$ a.s.l.). The horizontal distance between the two stations was 5 $\mathrm{km}$. The retrieved data allowed us to observe both the structure of the Bora airflows along the lee mountain side as well as temporal dynamics of mountain waves above the valley.

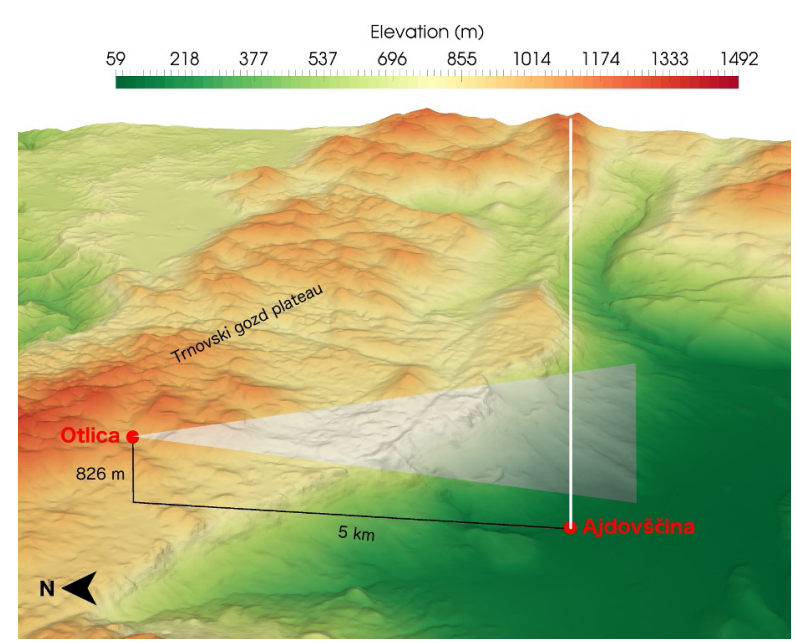

Fig. 2. Orography of the Vipava valley and the lee side of the Trnovski gozd plateu. Monitoring stations (Otlica and Ajdovščina) are marked by red points. The lidar at Otlica was oriented with the wind towards Ajdovščina and was scanning elevations between $12^{\circ}$ and $-5^{\circ}$ (shaded area). The lidar at Ajdovščina was stationary and pointed towards the zenith (white line).

\subsection{Instrumentation}

The self-developed scanning Mie-scattering lidar at Otlica, operating at $1064 \mathrm{~nm}$ with $10 \mathrm{~Hz}$ repetition rate [8] was oriented towards Ajdovščina (azimuth $225^{\circ}$ ) and retrieved twodimensional scans of aerosol loading distributions for elevation angles between $12^{\circ}$ and $-5^{\circ}$ with $0.1^{\circ}$ step. Each scan took about 4 minutes. It was also used in fixed mode at $0^{\circ}$ to provide 10 minute long time series of horizontal aerosol loading distribution between Otlica and Ajdovščina. The self-developed vertical lidar at Ajdovščina, operating at $1064 \mathrm{~nm}$ with $10 \mathrm{~Hz}$ repetition rate [9] was used to retrieve temporal dynamics of vertical atmospheric structure above the valley. Both lidars were deployed indoors and were not directly mechanically affected by Bora. Backscattering signals were averaged over 10 consecutive laser shots, digitized with range resolution of $3.75 \mathrm{~m}$ and range square corrected. In addition to remote sensing, wind speed and directions were monitored at both sites by twodimensional Vaisala WMT700 ultrasonic wind sensors. At Ajdovščina, wind data was available with a 1 second temporal resolution, while the sensor at Otlica provided average wind speed and direction as well as maximum gust speed and direction for 10 minute intervals.

\subsection{Experimental details}

The measurements took place on 24-25 January 2019 in neutral atmosphere conditions. Synoptic situation with a deep cyclone in central Mediterranean resulted in a typical Bora situation causing moderate wind gusts also in Vipava valley (Fig. 1). The predominant wind direction at Ajdovščina was NE ( $\mathrm{N}$ at Otlica) with average wind speeds of $10 \mathrm{~m} / \mathrm{s}$ and peaks of about $20 \mathrm{~m} / \mathrm{s}$. Thirty lidar scans were performed at Otlica with the aim to retrieve airflow characteristics. In order to estimate the effects of scan duration on the observed structures, the measurements were performed with alternating scanning directions. Properties of mountain waves arising from a hydraulic jump about $150 \mathrm{~m}$ below the observatory were extracted from five horizontal time series measurements. Periods and amplitudes of mountain waves were extracted from vertical measurements at Ajdovščina, which are available for the entire two-day period. 


\section{Results}

Stratified atmospheric layers with periodic atmospheric structures were observed in vertical lidar data throughout the Bora outbreak at the height of the Trnovski gozd ridge and below (Fig. 4, (a)) with typical amplitudes of about $100 \mathrm{~m}$. The most significant period of the mountain waves above Ajdovščina was found to be $180 \mathrm{~s}$, with the presence of considerably shorter periods (Fig. 4, (b)).

In order to investigate if the origin of mountain waves at heights considerably lower than the orographic barrier may be attributed to hydraulic jumps in the Bora flow, we investigated the presence of such jumps in two dimensional vertical lidar scans (Fig. 3). A hydraulic jump was observed at horizontal distance of about $1.5 \mathrm{~km}$ from the lidar site, where the about $100 \mathrm{~m}$ thick aerosol rich downslope Bora flow layer of cold air

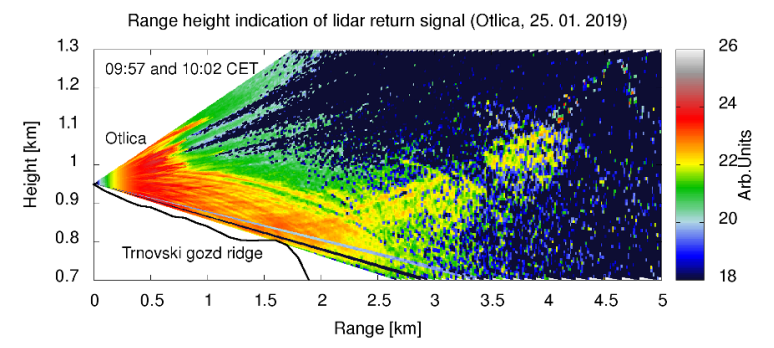

Fig. 3. Range-height indication of aerosol loading at Otlica on 25 January 2019. Two subsequent lidar scans were merged in this plot, an upward scan from $-5^{\circ}$ to $12^{\circ}$ at 09:57 and a downward scan from $12^{\circ}$ to $-5^{\circ}$ at 10:02 CET to minimize scanning direction effects.

rose higher above the surface due to a secondary ridge about $150 \mathrm{~m}$ below Otlica. In order to confirm that the observed jump of cold air masses gave rise to mountain waves, we searched for periodic structures in the horizontal profiles from Otlica, which captured the dynamics of aerosol loading $150 \mathrm{~m}$ above the jump. The lidar trace was found to reach through a number of waves
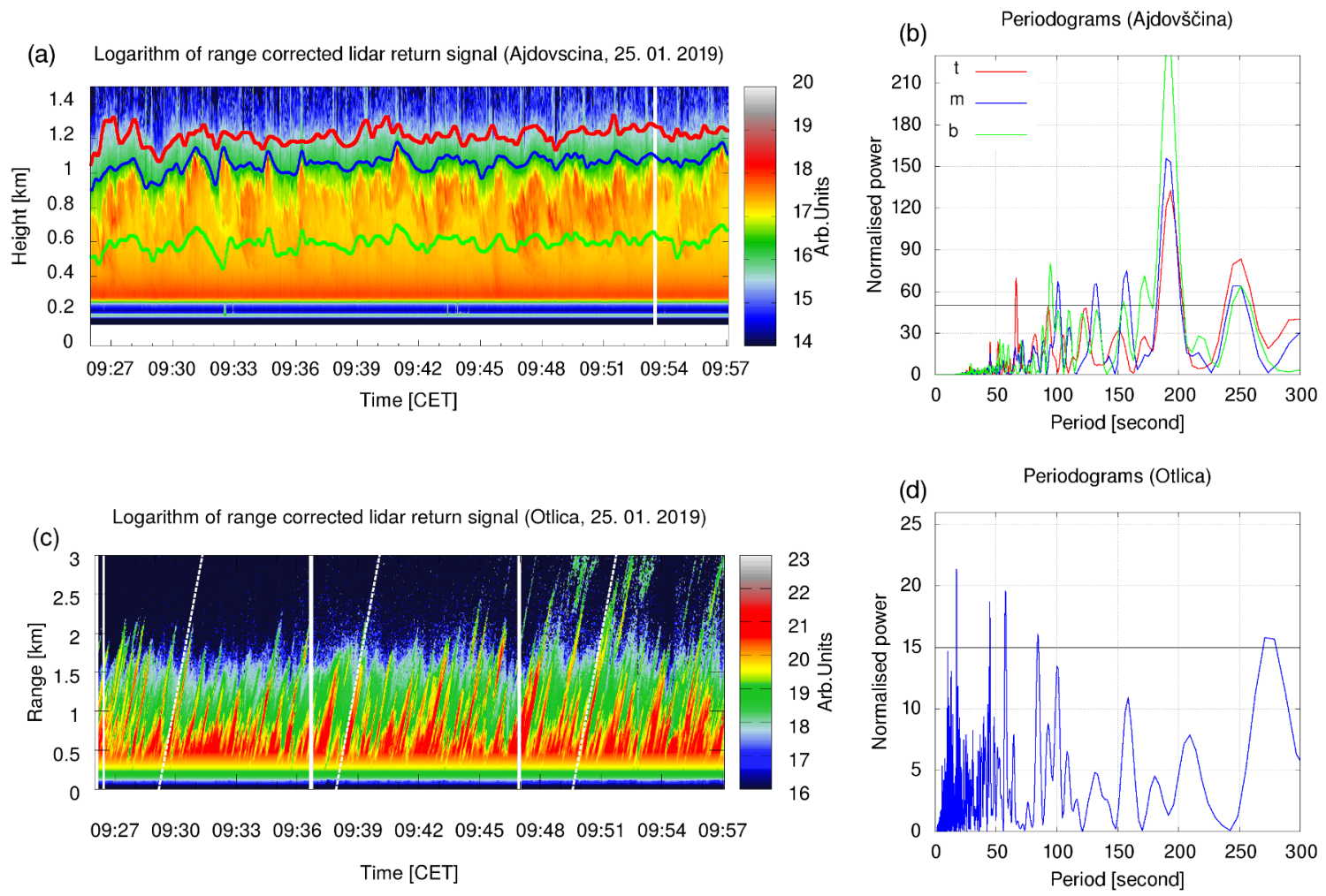

Fig. 4. a) Temporal evolution of vertical aerosol loading profiles at Ajdovščina. Air mass streamlines at different heights are denoted by solid lines; c) Temporal evolution of horizontal aerosol loading profiles at Otlica. The observed structures are inclined at $23 \mathrm{~m} / \mathrm{s}$ (denoted by dashed white line); b) periodogram of the extracted streamlines, obtained using least square spectral analysis method; d) periodogram of the observed peaks in horizontal profiles. Black horizontal lines represent 0.001 significance level. 
propagating away from the mountain side (Fig. 4, c). The most significant period of the observed structures was found to be as short as $18 \mathrm{~s}$, which may be attributed to local micro-orographical terrain features of this particular jump. They were all found to be inclined at the same angle of 23 $\mathrm{m} / \mathrm{s}$, which represents horizontal wave propagation speed. Constant wave propagation speed is an indication that Taylor's frozen turbulence hypothesis is an appropriate assumption for the description of mountain wave propagation during Bora episodes. Furthermore, spatial periodic structure of aerosol loading was revealed by sampling of horizontal profiles with the same phase (with $18 \mathrm{~s}$ intervals between them). A delay of the starting time of profile sampling caused the wave to move away from the jump. Relative delay of $9 \mathrm{~s}$ between start times of two samplings yielded waves with opposite $\left(180^{\circ}\right.$ shifted) phases (Fig. 5). In both cases, the wavelength was about $400 \mathrm{~m}$, which is in agreement with the retrieved propagation speed and period of the waves.

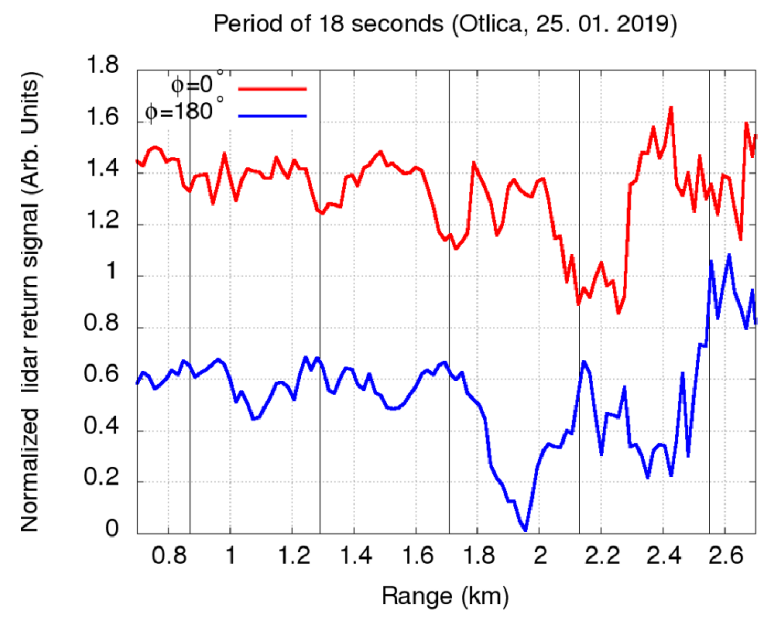

Fig. 5. Using the same data as presented in Fig. 4c, range square corrected horizontal lidar returns with the same mountain wave phase (occurring every $18 \mathrm{~s}$ ) were added, corrected for the attenuation and normalized. Blue and red line represent waves shifted for half a period ( $9 \mathrm{~s})$, which are manually vertically offset by 0.8 for easier viewing. Vertical lines denote peak-to-peak distance (wavelength) of $400 \mathrm{~m}$.

\section{CONCLUSIONS}

Two coordinated lidar measurements providing simultaneous vertical and horizontal airflow dynamics allowed us to directly observe and quantify the parameters of mountain waves, which appeared during a Bora episode above and at the lee side of the Trnovski gozd plateau. We identified a hydraulic jump of cold, narrow layer of Bora flow descending downslope the lee side of the mountain as a source of mountain waves at a hight well below the top of the orographic barrier. The propagation speed of these waves was found to be constant at $23 \mathrm{~m} / \mathrm{s}$ (at a higher speed than wind speed at Otlica) and their wavelength was approximately $400 \mathrm{~m}$ with a period of $18 \mathrm{~s}$. The constant propagation speed allows us to use Taylor's frozen turbulence hypothesis for estimating horizontal propagation of mountain waves. Based on vertical lidar data, which yielded the most significant periodicity of $180 \mathrm{~s}$ at the height of the orographic barrier, and under the assumption that wave propagation speed is the same as for waves observed at lower heights, the wavelength for these waves was estimated to be about $4 \mathrm{~km}$. As a next step, mountain waves will be investigated using a combination of stereo lidar measurements, large-eddy CFD simulations and high resolution numerical weather prediction modeling to interpret the observations.

\section{ACKNOWLEDGEMENTS}

This work was supported by the Slovenian Research Agency (grant number P1-0385) and Fulbright Scholar program.

\section{REFERENCES}

[1] L. Strauss, et al., J. Atmos. Sci. 73.4, 1481-1506 (2016).

[2] M. Yoshino, Local Wind Bora. University of Tokyo Press, 1976.

[3] T.N. Palmer, et al., Q. J. R. Meteorol. Soc. 112, 1001-1039 (1986)

[4] J. Kuettner, et al., Bull. Am. Meteorol. Soc. 62, 793-805 (1981).

[5] A.Tsiringakis, et al., Q. J. Meteorol. Soc. 143.704, 1504-1516 (2017).

[6] R.B. Smith, et al., J. Atmos. Sci. 42, 2597-2603 (1985)

[7] M. Mole, et al., J. Quant. Spect. Radiat. Trans. 188, 39-45 (2017).

[8] T-Y. He, et al., Proc. SPIE, 7832, 7832U (2010).

[9] L.Wang, et al., Atmosphere, 10, 128 (2019). 